Swarthmore College

Works

2-27-1989

\title{
Optogalvanic Signals From Argon Metastables In A Rf Glow- Discharge
}

D. E. Murnick

R. B. Robinson

D. Stoneback

M. J. Colgan

Frank Moscatelli

Swarthmore College, fmoscat1@swarthmore.edu

Follow this and additional works at: https://works.swarthmore.edu/fac-physics

Part of the Physics Commons

Let us know how access to these works benefits you

\section{Recommended Citation}

D. E. Murnick, R. B. Robinson, D. Stoneback, M. J. Colgan, and Frank Moscatelli. (1989). "Optogalvanic Signals From Argon Metastables In A Rf Glow-Discharge". Applied Physics Letters. Volume 54, Issue 9. 792-794. DOI: 10.1063/1.100848

https://works.swarthmore.edu/fac-physics/88

This work is brought to you for free by Swarthmore College Libraries' Works. It has been accepted for inclusion in Physics \& Astronomy Faculty Works by an authorized administrator of Works. For more information, please contact myworks@swarthmore.edu. 


\section{A|P |Applied Physics Letters}

\section{Optogalvanic signals from argon metastables in a rf glow discharge}

D. E. Murnick, R. B. Robinson, D. Stoneback, M. J. Colgan, and F. A. Moscatelli

Citation: Applied Physics Letters 54, 792 (1989); doi: 10.1063/1.100848

View online: http://dx.doi.org/10.1063/1.100848

View Table of Contents: http://scitation.aip.org/content/aip/journal/apl/54/9?ver=pdfcov

Published by the AIP Publishing

\section{Articles you may be interested in}

The role of carrier gases in the production of metastable argon atoms in a rf discharge

Rev. Sci. Instrum. 80, 036105 (2009); 10.1063/1.3105722

Modeling characteristics of nonequilibrium processes during breakdown of capacitive rf argon glow discharge Phys. Plasmas 15, 053507 (2008); 10.1063/1.2918660

Optogalvanic effect and measurement of gas temperature in an abnormal glow discharge Appl. Phys. Lett. 89, 131502 (2006); 10.1063/1.2352793

Role of the fast Ar atoms, $\mathrm{Ar}+$ ions, and metastable Ar atoms in a hollow cathode glow discharge: Study by a hybrid model

J. Appl. Phys. 94, 2212 (2003); 10.1063/1.1594276

A rf discharge cell for saturated absorption spectroscopy of metastable argon

Rev. Sci. Instrum. 73, 493 (2002); 10.1063/1.1433953

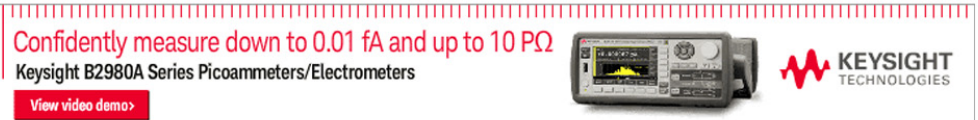




\title{
Optogalvanic signals from argon metastables in a rf glow discharge
}

\author{
D. E. Murnick, ${ }^{2)}$ R. B. Robinson, and D. Stoneback ${ }^{\text {bj }}$ \\ AT\&T Bell Laboratories, Murray Hill, New Jersey 07978
}

M. J. Colgan

Department of Physics, Rutgers University, Piscataway, New Jersey 09854

F. A. Moscatelli

Department of Physics, Swarthmore College, Swarthmore, Pennsylvania 19081

(Received 28 November 1988; accepted for publication 13 December 1988)

Laser optogalvanic (LOG) signals at $667.7,751.5$, and $696.5 \mathrm{~nm}$ from the ${ }^{3} P_{1}$ and ${ }^{3} P_{2}$ levels of

Ar were studied at a pressure of $250 \mathrm{~m}$ Torr in a of glow discharge. Signals with unexpected signs and time dependences were found. The results are interpreted as being due to radiative trapping effects and collisional mixing between resonance and metastable levels. An average electron energy of $2.1 \mathrm{eV}$ is derived from modeling the data.

Glow discharges driven by radio frequency power supplies are of fundamental as well as practical interest. ${ }^{1,2}$ Laser optogalvanic (LOG) spectroscopy, particularly of rare gas discharges and mixed discharges with the rare gas as a dominant component, has provided useful diagnostics of discharge processes. ${ }^{3}$ Spatiai ${ }^{4}$ and temporal ${ }^{5}$ measurements using both $\mathrm{cw}$ and pulsed lasers have played an important role in elucidating discharge mechanisms and energy storage and transfer pathways. We have carried out LOG studies in a ff glow discharge using the $696.5 \mathrm{~nm}\left(1 s_{5}-2 p_{2}\right)$, the $667.7 \mathrm{~mm}$ $\left(1 s_{4}-2 p_{1}\right)$, the $751.5 \mathrm{~nm}\left(1 s_{4}-2 p_{5}\right)$, and the $604.3 \mathrm{~nm}\left(2 p_{8}-\right.$ $5 d_{4}$ ) transitions in argon. In many respects these LOG signals behave very differently from similar transitions in neon which has served, until now, as a paradigm for modeling the optogalvanic effect ${ }^{5-7}$ at low pressures. The $696.5 \mathrm{~nm}$ LOG signal, for example, is much weaker and of opposite sign compared to the exactly analogous transition in neon (588.1 $\mathrm{nm})$. The $667.7 \mathrm{~nm}$ transition originating from the nonmetastable $1 s_{4}$ level is strong and of the same sign as transitions from the $1 s_{3}$ and $1 s_{5}$ metastable levels in neon. The argon 751.5 and $667.7 \mathrm{~nm}$ transitions, which share the same lower level, have LOG signals of opposite signs. Such a difference in signs in LOG signals of transitions originating from the same lower level has never been observed in comparable neon discharges. The detailed measurements and modeling described in this letter allow a new understanding of the rf argon glow and provide a physical model of the LOG effect in argon which can be exploited for actinometric applications and a more complete understanding of atom and electron kinetics.

Argon, with its closed shell, inert-gas level structure, has its four lowest excited levels due to the $3 p^{5} 4 s$ configuration, shown along with some levels of the $3 p^{5} 4 p$ group in Fig. 1. The two transitions from the $1 s_{4}$ level complement each other as optogalvanic probes in that the $667.7 \mathrm{~nm}$ line effectively transfers population from the ${ }^{3} P_{1}$ resonance level to the ' $P_{1}$ level whereas the $751.5 \mathrm{~nm}$ line essentially only couples the ${ }^{3} P_{1}$ state to the $2 p_{5}$ level. The $696.5 \mathrm{~nm}$ transition

i) Present address: Department of Physics, Rutgers University, Newark, NJ 07102.

"' Permanent address: Westfield High School, Westifeld. NJ 07090. from the lowest metastable state has branches from the $4 p$ manifold to all four levels in the $4 \mathrm{~s}$ manifold.

The experiments were carried out in a weak rf glow discharge driven by a Coipitts oscillator ${ }^{8}$ or a new solid-state

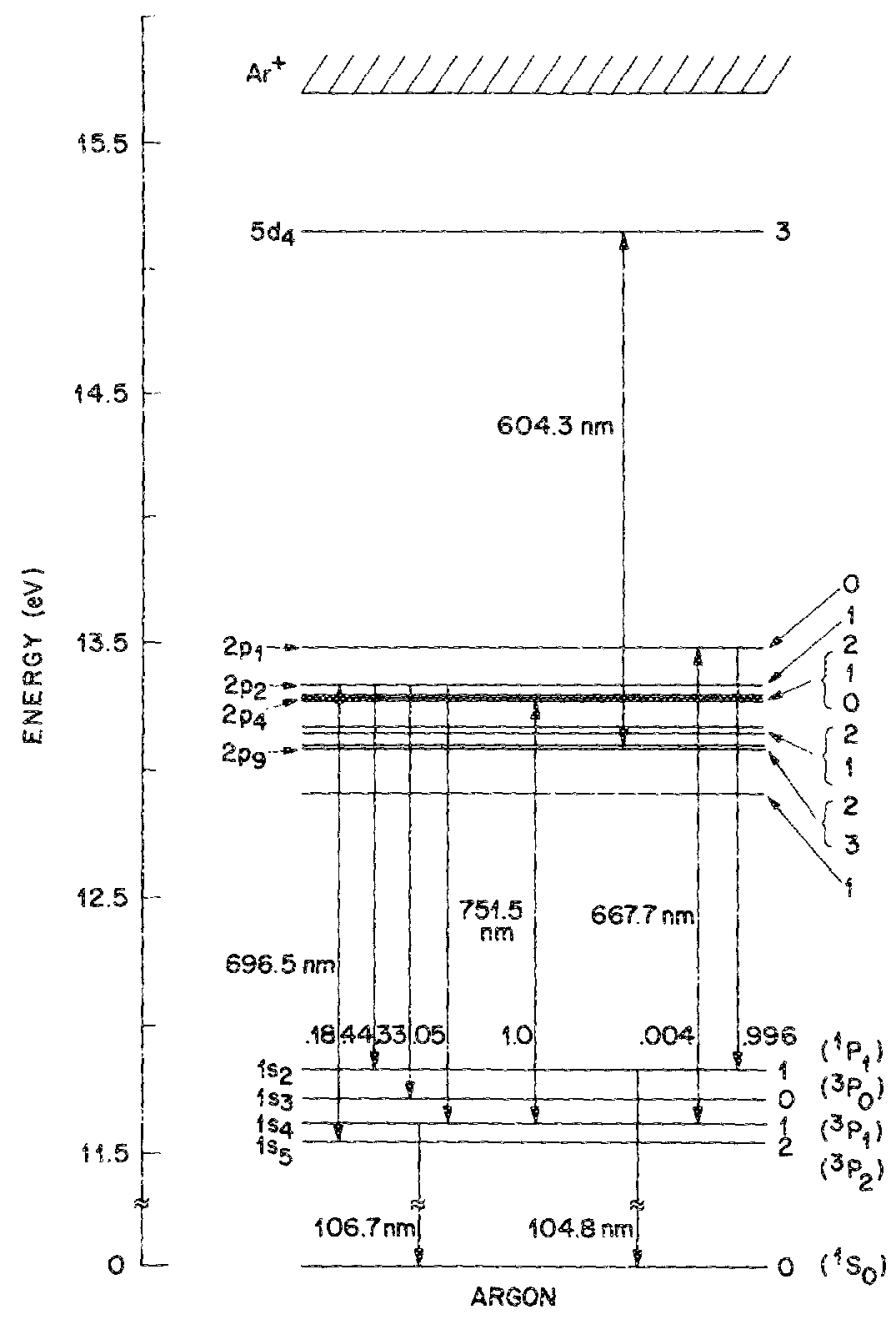

FIG. 1. Partial energy level diagram of argon (not to scale) showing relevant transitions. Laser and resonance lines are given in $\mathrm{nm}$ and branching ratios are indicated. LS coupling, total angular momentum $J$, and Paschen notation are listed. 
oscillator. ${ }^{9}$ In both cases the LOG signal was monitored by changes in oscillator circuit voltages which vary with the discharge impedance. Pure argon gas was slowly flowed through the cell at regulated pressures from about $50 \mathrm{~m}$ Torr to 1 Torr. Single mode tunable hasers using DCM, thodamine $6 \mathrm{G}$, or pyridine 2 dye, were employed allowing accurate line shape measurements of the Doppler broadened spectra. Standard lock-in signal averaging techniques were used in recording data with the laser frequency scamed under computer contol. In addition, with the laser frequency fixed, the time evolution of the LOG signal was obtained using a Pockels cell or a mechanical chopper to switch the laser beam on and off with a boxcar integrator also under computer control.

The optogalvanic signals for the $696.5,667.7$, and 751.5 $\mathrm{nm}$ zransitions as a function of time are shown in Fig. 2 at a pressure of $250 \mathrm{~m}$ Torr. The chopping rate and duty cycie were chosen to ensure that equilibrium was reached both with the laser on and off. In each case the laser is frequency locked to the center of the Doppler broadened resonance $( \pm 10 \mathrm{MHz})$ and the power was held below saturation for the transition. The $667.7 \mathrm{~nm} \log$ signal is seen to be composed of a negative and a positive signal of different magnitudes and time evolutions. ${ }^{10}$ Ir: our experimental arrangement, a negative ontogaivanic signal is indicative of enhanced discharge conductivity. Note that irradiation with light at $667.7 \mathrm{~nm}$ causes rapid transfer of population from the $1 s_{4}\left({ }^{3} P_{1}\right)$ resonance level to the $2 p_{1}(J=0)$ level from which the population can relax through spontaneous emission, primarily to the other resonance level ( $\left.P_{1}\right)$.

In the case of irradiation at $696.5 \mathrm{~nm}$, metastable population from the $1 s_{5}\left({ }^{3} P_{2}\right)$ level is redistributed, via the intervening $2 p_{2}(J=1)$ state, almost equally to the other metastable state $\left(1 s_{3}\right.$ or $\left.{ }^{3} P_{0}\right)$ and the resonance level $\left(1 s_{2}\right.$ or $\left.{ }^{1} P_{1}\right)$. The $696.5 \mathrm{~nm}$ LOG signal is also composed of a negative and a positive component of relative signs and magnitudes quite different from $667.7 \mathrm{~nm}$. In particular, the steady-state signal is observed to be of the opposite sign and nearly a factor of 10 smaller than the $667.7 \mathrm{~nm}$ signal (when normalized to matrix elements and laser power).

The LOG signal corresponding to the $751.5 \mathrm{~nm}$ transi-

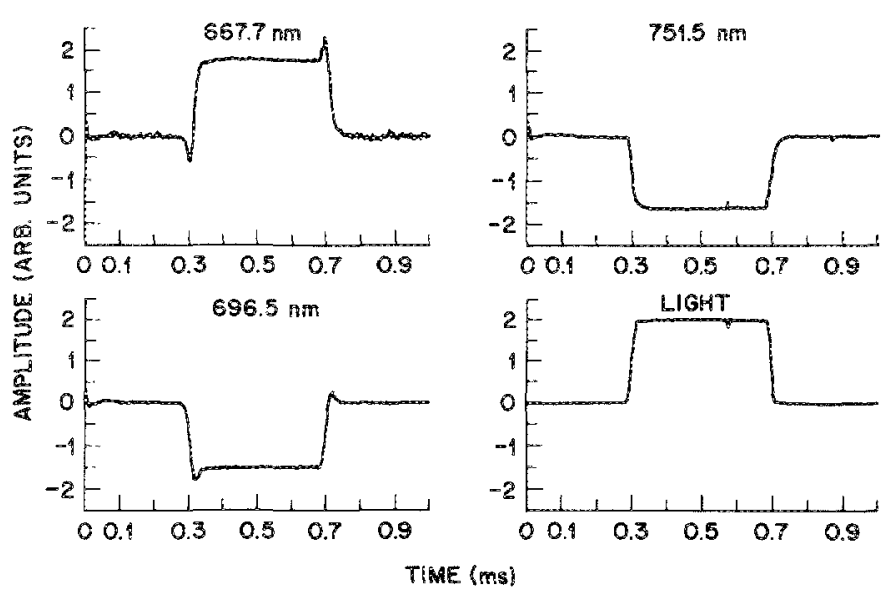

FIG. 2. Time-dependent LOG signal for $667.7,696.5$, and $751.5 \mathrm{~nm}$ transitions. The light pulse is shown for comparison. tion is of a sign opposite that of the $667.7 \mathrm{~nm}$ transition even though both originate with the $1 s_{4}$ level. Finally, we note that the LOG signal as a function of time for the $604.3 \mathrm{~nm}$ transition essentially followed the laser timing. This transition is between the $2 p_{8}(J=2)$ level of the $3 p^{5} 4 p$ configuration and the $5 d_{4}(J=3)$ level of the $3 p^{5} 5 d$ configuration. Neither configuration invoives any metastable states directly, and the LOG signal is of only one sign showing increased conductivity. Analogous transitions in neon behave similarly. Increased conductivity is primarily cue to enhanced ion:zation from levels nearer to the continuum. Ionization from excited states dominates the optogalvanic effect signal when pumping to levels 1 or $2 \mathrm{eV}$ below the $\mathrm{Ar}^{+}$continuum.

Decreased conductivity is primarily due to a loss of metastables, which are the primary energy reservoirs in the system. Important reactions involving the metastables include

$$
\mathrm{Ar}^{m}+e \rightarrow \mathrm{Ar}^{+}+2 e
$$

and

$$
\mathrm{Ar}^{m}+e-\mathrm{A} \mathbf{r}^{*}+e^{\prime}
$$

where included in reaction (2) are $1 s_{5} \rightarrow 1 s_{4}$ transfers in which the metastable atom is converted to a UV emitter. The loss of energy through UV emission by the $1 s_{4}$ atoms thus represents an indirect loss of metastables and should lead to decreased conductivity. The equilibrium densities of $1 s_{5}$ and $1 s_{4}$ aroms were absolutely determined, for approximately constant rf power, by optical absorption measurements at 696.5 and $751.5 \mathrm{~nm}$, respectively, to be $8 \times 10^{10}$ and $2 \times 10^{10} / \mathrm{cm}^{3}$ at $250 \mathrm{mTorr}$. The $1 s_{3}$ and $1 s_{2}$ densities were similarly measured by absorption at 772.4 and $750.4 \mathrm{~nm}$ to be $1.5 \times 10^{10}$ and $0.6 \times 10^{10} / \mathrm{cm}^{3}$.

The relatively high population of the $1 s_{4}$ level is due both to reactions of type (2) above and the effect of radiation trapping. The optogalvanic signal from the $667.7 \mathrm{~mm}$ transition is especially sensitive to differences in radiation trapping between the two resonance UV lines. Using the relationship for imprisonment decay constants for a cylindrical geometry under conditions of collision type emission with Doppler broadened absorption, ${ }^{11,12}$ we calculate trapping times of 10 $\mu$ f for the $106.7 \mathrm{~nm}$ radiation and $1.8 \mu$ s for the $104.8 \mathrm{~nm}$ radiation. Thus the cransfer from one resonance level to the other (purnping at $667.7 \mathrm{~nm}$ ) leads to a five times faster loss of UV and indirect loss of metastables.

We interpret the initial increased conductivity (Fig. 2) with laser turn-on in all three cases as being due to enhanced ionization from the states nearer the continuum in the $4 p$ manifold $\left(2 p_{1}-2 p_{9}\right)$. The larger steady state decreased conductivity in the $667.7 \mathrm{~nm}$ transition results from UV loss from the discharge due to less trapping of $104.8 \mathrm{~nm}$ radiation compared to $106.7 \mathrm{~nm}$ as well as due to an indirect loss of metastables. The indirect loss is aue to the electron collisional exchange between metastable and resonance levels which maintains an equilibrium population in the $4 s$ manifold. Using data for electron collision rate constants from the literature, ${ }^{13}$ we estimate mixing rates of resonance and metastable levels in the glow discharge to be of order $10^{4} \mathrm{~s}^{-1}$. Pumping at $667.7 \mathrm{~nm}$ disturbs the equilibrium established in the plasma and leads to a loss of metastables, which are the 
primary energy reservoir in the system, hence to a lower conductivity. The $35 \mu$ s relaxation of the positive signals (Fig. 2) is die to the reestablishment of equilibrium in the presence of the laser pumping.

The high positive LOG effect for 751.5 and $696.5 \mathrm{~nm}$ indicates the importance of ionization from the $4 p$ manifold in the present discharge. The electron energy distribution is peaked at low energy in the rf discharge as evidenced by the mixing rate of metastable and resonance transitions and the strong positive optogalvanic effect in pumping to the $4 p$ manifold. The metastable temperature is $300 \mathrm{~K}$ as determined from the measured Doppler widths of the LOG yransitions.

Using a set of coupled rate equations which incorporate various rate constants, ${ }^{13}$ diffusion constants, ${ }^{13}$ and excitation and ionization cross sections ${ }^{14.17}$ from the literature with an ionization balance constraint, we have obtained good agreement to the measured densities of metastabie and first resonance level atoms. A Maxwellian electron energy distribution function was assumed with the best-fit density and average temperature being $1.6 \times 10^{10} / \mathrm{cm}^{3}$ and $2.1 \mathrm{eV}$, respectively. The calculations imply that the $1 s_{4}: 1 s_{5}$ population ratios are due to a balance between radiation trapping and metastable resonance level mixing. These are the same effects which are the major contributors to the anomalous LOG signals observed.

In summary, we have presented LOG data on argon glow discharges which are contrary to the general systematics for such effects deduced from many neon experiments. The results are understandable in terms of radiative trapping and electron mixing collision effects. Further experiments to study the detailed spatial, pressure, and time dependences of LOG signals in the rf glow discharge are in progress and should lead to better modeling, the development of discharge diagnostics, and an improved understanding of the radiative trapping effect.

W. R. Softky participated in preliminary measurements, and helpful discussions were held with $\mathrm{R}$. Gottscho. One of us (F.A.M.) acknowledges the undergraduate research assistance of J. A. Ruff and B. E. Spear and the technical support of J. Andrews and J. Dougherty. F. A. M. was supported in part by a William and Flora Hewlett Foundation Grant from the Research Corporation and the Swarthmore College Research Support Committee.

J. E. Lawler, A. I. Ferguson, J. E. M. Goldmith, D. J. Jackson, and A. L. Schawlow, Phys. Rev. Letl. 42, 1046 (1979).

'Brian Chapman, Glow Discharge Process (Wiley, New York, 1980).

${ }^{3}$ C. E. Gabe and R. A. Gottscho, in Radiative Processes in Discharge Plasmas, edited by J. M. Proud and L. H. Luessen (Plenum, New York, 1986), p. 495 ; B. N. Gaugoly and A. Garscadden, Appl. Phys. Lett. 46, 540 (1985).

${ }^{4}$ K. Tochigi, S. Maedo, and C. Hirose, Phys. Rev. Lett. 57, 71 (1986). The oscillations noted in this paper may be explained by electronies oscillation: see S. P. L.e, E. W. Rothke, and G. R. Reck, J. Appl. Phys. 61, 109 (1987).

A. Ben-Amar, G. Erez, and R. Shuker, J. Appl. Phys. 54, 3688 (1983).

${ }^{6}$ D. K. Doughty and J. E. Lawler, Phys. Rev. A 28, 773 (1983).

${ }^{7}$ K. C. Smyth, R. A. Keller, and F. C. Crim, Chem. Phys. Lett. 55, 473 (1978).

${ }^{8}$ D. R. Lyons, A. L. Shawlow, and G. Y. Yan, Opt. Commun. 38, 35 (1981).

${ }^{9}$ R. D. May and P. H. May, Rev. Sci. Instrum. 57, 2242 (1986).

The first report of a positive LOG signal for this transition, D. E. Murnick, W. R. Softky, and D. N. Stoneback, Phys. Lett. B 174, 238 (1986), incorrectly interpreted the average positive $\mathrm{LOG}$ signal as being due to an inverted population.

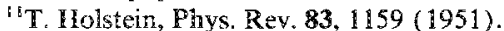

'2P. J. Walsh, Phys. Rev. 116, 511 (1959).

1.3O. P. Bochkova and E. A. Sukiasyan, Z. Prikl. Spek. 23, 601 (1975).

${ }^{14}$ K. Tachibana, Phys. Rev. A 34, 1007 (1986)

${ }^{15}$ H. A. Hyman, Dhys. Rev. A 20,855 (1979).

1611. A. Hyman, Phys. Rev. A 18, 441 (1978).

${ }^{17}$ D. Rapp and P. Englander-Golden, J. Chem. Phys. 43, 1464 (1965). 